\title{
Prolonged High Dose Esomeprazole for the Treatment of Chronic Cough in an Israeli Adult Population - An Open Label Study
}

\section{Ram Dickman ( $\sim$ dickmanr1@gmail.com )}

Division of Gastroenterology, Rabin Medical Center, Beilinson Campus and Sackler Faculty of Medicine, Tel Aviv University

\section{Doron Boltin}

Division of Gastroenterology, Rabin Medical Center, Beilinson Campus and Sackler Faculty of Medicine,

Tel Aviv University

\section{Rachel Gingold-Belfer}

Division of Gastroenterology, Rabin Medical Center, Beilinson Campus and Sackler Faculty of Medicine,

Tel Aviv University

\section{Yona Vaisbuch}

Department of Otolaryngology-Head and Neck Surgery, Rabin Medical Center, Beilinson Campus and Sackler Faculty of Medicine, Tel Aviv University

\section{Yuval Nachalon}

Department of Otolaryngology-Head and Neck Surgery, Rabin Medical Center, Beilinson Campus and Sackler Faculty of Medicine, Tel Aviv University

\section{Amit Ritter}

Department of Otolaryngology-Head and Neck Surgery, Rabin Medical Center, Beilinson Campus and Sackler Faculty of Medicine, Tel Aviv University

\section{Jacob Shvero}

Department of Otolaryngology-Head and Neck Surgery, Rabin Medical Center, Beilinson Campus and Sackler Faculty of Medicine, Tel Aviv University

\section{Amani Bshara}

Division of Gastroenterology, Rabin Medical Center, Beilinson Campus and Sackler Faculty of Medicine, Tel Aviv University

\section{Uri Alkan}

Department of Otolaryngology-Head and Neck Surgery, Rabin Medical Center, Beilinson Campus and Sackler Faculty of Medicine, Tel Aviv University

\section{Research Article}


Keywords: Chronic cough, Gastroesophageal reflux disease, Hoarseness, Postcricoid hyperemia, Proton pump inhibitors

Posted Date: April 8th, 2021

DOl: https://doi.org/10.21203/rs.3.rs-378690/v1

License: (1) This work is licensed under a Creative Commons Attribution 4.0 International License. Read Full License 


\section{Abstract \\ Background}

Chronic cough is considered to be part of the gastroesophageal reflux disease (GERD) spectrum. However, the response rate to standard dose proton pump inhibitors (PPI's) is poor. Our aim was to evaluate the response rate of chronic cough to an extended course of high dose PPI's and to identify predictors of treatment response.

\section{Methods}

This prospective study included adult nonsmoking patients with chronic cough, normal spirometry, normal upper endoscopy and with no evidence of postnasal drip (PND). Treatment consisted of high dose PPI's (esomeprazole, $40 \mathrm{mg}$ b.i.d.) for 4 months. Primary end point was the reduction of the Reflux Symptoms Index (RSI), Leicester Cough Questionnaire (LCQ) and the Reflux Findings Score (RFS) by more than $50 \%$ at 4 months from baseline.

\section{Results}

Forty-one patients ( $39 \%$ female; mean age $55.9 \pm 15.19$ years) were enrolled, most of them with mean cough duration of more than 1 year. The primary end point was achieved in $39 \%$ of patients. Predictors of response included higher educational level $(p=0.035)$, hyperemia of the arytenoids and the postcricoid area $(p=0.026)$, and hoarseness $(p<0.01)$. No difference was found in the frequency of heartburn and regurgitation between responders and nonresponders. More complaints of difficulty in swallowing were reported by nonresponders $(p<0.01)$.

\section{Conclusion}

A therapeutic benefit of high dose PPI's for chronic cough cannot be dismissed, especially in patients with hoarseness, and arytenoid or postcricoid hyperemia. Prolonged high dose therapy may be warranted.

\section{Key Summary}

1. The established knowledge on this subject:

- Together with upper airway cough syndrome and asthma, gastroesophageal reflux disease (GERD) accounts for the majority of cases of chronic cough

- Diagnosis of GERD-induced chronic cough is challenging, as up to 70\% of GERD patients with chronic cough do not report heartburn and/or regurgitation 
- GERD may cause chronic cough by direct (contact of acidic or nonacidic refluxate) and indirect (vagally mediated reflex) mechanism

- The response rate of chronic cough to PPI therapy is unpredicted and suboptimal

2. The significant new findings of this study?

- Presence of hoarseness, hyperemia of the arytenoids and postcricoid area, and lack of dysphagia are positive predictive factors for PPI response

- Presence of dysphagia is a negative predictive factor for PPI response

- Patients who respond to therapy in the first 2 months benefit from continuing treatment for an additional 2 months

- There is no basis to continue PPI therapy if there is a lack of response at 2 months

\section{Background}

Chronic cough, defined as cough that persists for more than 8 weeks, affects $11-20 \%$ of the adult population and may significantly impair quality of life [1, 2]. Upper airway cough syndrome, asthma, and gastroesophageal reflux disease (GERD) account for the majority of cases of chronic cough.

GERD typically manifests as heartburn and/or regurgitation. Atypical or extraesophageal manifestations may occur, such as chronic cough, non-cardiac chest pain, throat clearing, hoarseness, dysphonia, asthma, and globus sensation [3]. Moreover, gastroesophageal reflux may cause chronic cough by two distinct mechanisms: 1) Direct contact of acidic or nonacidic refluxate (bile, pepsin, duodenal enzymes) that reaches the proximal esophagus and then the larynx [4]; 2) Indirectly, cough may be due to a vagally mediated reflex, initiated in the distal esophagus by gastric contents that stimulate mucosal receptors [4.5].

In several studies, acid infusion into the distal esophagus significantly increased cough frequency in patients with GERD and chronic cough [6.7]. Furthermore, ambulatory acoustic cough monitoring with simultaneous impedance/pH recording, demonstrated that cough was positively associated with excessive esophageal acid exposure [8]. Nevertheless, diagnosis of GERD-induced chronic cough is challenging, as up to $70 \%$ of gastroesophageal reflux patients with chronic cough do not report typical GERD symptoms (heartburn and regurgitation) [9]. In addition, the response rate of chronic cough to proton pump inhibitor (PPI) therapy, which represents the standard of care for GERD, is suboptimal [10.11].

These observations may indicate that the working diagnosis (i.e., cough is GERD-related) is incorrect, or some cases of PPI failure are due to suboptimal acid suppression.

In clinical practice, in the absence of pulmonary disease or sinusitis/post nasal drip (PND), most physicians will suspect GERD and treat chronic cough with standard or even double doses of PPI's. However, there are no prospective studies that have evaluated the effectiveness of double dose PPIs in 
patients with chronic cough. The aims of this study were to evaluate effectiveness of double dose PPI therapy for the treatment of chronic cough, and to identify predictive factors of response to PPI therapy.

\section{Methods}

\section{Patients}

Nonsmoking patients (age $>18$ years) with a history of chronic cough

(>8 weeks) during the 6 months prior to screening, without established PND or pulmonary disease, were eligible for enrollment. All eligible patients were previously assessed in the Otolaryngology and Pulmonology Clinics at the Rabin Medical Center to exclude otolaryngeal or pulmonary pathology. Referral of patients for screening was performed by otorhinolaryngologists and gastroenterologists from the Otorhinolaryngology and Gastroenterology outpatient clinics, respectively, at the Rabin Medical Center. Exclusion criteria included gastric or esophageal surgery, active peptic ulcer disease, malignancy, endoscopic evidence for erosive esophagitis, or Barrett's esophagus. In addition, we excluded pregnant patients, active smokers, patients with asthma, chronic bronchitis, or pathologic findings on spirometry or chest X-ray, patients with gastroparesis and those on active treatment with angiotensin-converting enzyme inhibitors. We also excluded patients reluctant or incapable of providing informed consent, unable to fully complete all phases of the study, or with a contraindication to PPI therapy.

\section{Study design}

This prospective, interventional open-label trial, was conducted between January 2013 to May 2016, in the Divisions of Otorhinolaryngology and Gastroenterology at the Rabin Medical Center, Israel, and was performed in accordance with the principles of the Declaration of Helsinki, Good Clinical Practice and was approved by the Human Subjects Protection Program of the Rabin Medical Center, Israel on $4^{\text {th }}$ of March 2013 (trial 0125-13).

All patients provided written informed consent before enrollment into the study. All eligible patients who gave informed consent underwent an upper endoscopy (at baseline only) if they had not done so in the past year.

This study adheres to CONSORT guidelines.

\section{Patient screening and enrollment}

After initial screening, patients with chronic cough were assessed during a face-to-face interview by one of the two chief investigators (R.D. and U.A.). This was performed to ensure that the inclusion and exclusion criteria were met, to obtain written informed consent, and to prescribe PPI therapy. Treatment comprised esomeprazole $40 \mathrm{mg}$ twice daily for a period of 4 months.

\section{Study instruments and measurements}


Patients were evaluated by questionnaires and by fiberoptic laryngoscopy at baseline, 2 months and 4 months after initiation of treatment. At each time point, patients were interviewed by chief investigators to obtain numerical responses to the items in the questionnaires.

\section{Demographic questionnaire}

The demographic questionnaire included characteristics regarding age, gender, body mass index, ethnicity, level of education, occupation, and marital status.

\section{Reflux symptoms index (RSI)}

The RSI is a 9-item self-administered outcome questionnaire designed to evaluate extraesophageal reflux related symptoms and severity. Symptoms include hoarseness, vocal fatigue, excessive throat clearing, dysphagia, chronic cough, and PND. Regurgitation and heartburn are also evaluated. Patients are asked to rate how these 9 symptoms have affected them over the past month on a scale of 0 (none) to 5 (severe), with a maximum total score of 45 . A total score of more than 13 is considered suggestive of extraesophageal reflux. The higher the score, the more severe the symptoms experienced by the patient [12].

\section{Leicester cough questionnaire (LCQ)}

The LCQ is a validated, self reported quality of life instrument comprising 19 items relating to three main domains: Physical, psychological, and social [13]. Patients are asked to rate the frequency and severity of symptoms on a 7-point Likert scale (ranging from 1 to 7). Scores are calculated as a mean of each domain, and the total score is calculated by adding every domain score. The lower the score, the greater the symptoms experienced by the patient.

\section{Fiberoptic laryngoscopic examination}

Fiberoptic laryngoscopic examination was performed at all 3 time points by the study investigators (Y.V. and U.A.) to evaluate the signs suggestive of reflux, and for completion of the Reflux Findings Score (RFS) [14]. If the vocal cords and surrounding structures were not clearly visible with a rigid endoscope, a flexible nasopharyngoscope was used. Participants were instructed to verbalize "ee" in a high-pitched, low-pitched, and regular-pitched tone.

\section{Reflux finding score (RFS)}

The RFS is an 8-item index designed to assess clinical severity based on laryngoscopic findings [14]. The 8 items included in the scale are subglottic edema, ventricular obliteration, erythema/hyperemia, vocal fold edema, diffuse laryngeal edema, posterior commissure hypertrophy, granuloma/granulation tissue, and excessive endolaryngeal mucus. Scores range from 0 (normal) to 26 (most severe). A score of 11 or above is suggestive of GERD.

\section{Statistical analysis}


A positive response to PPI treatment was defined as an improvement of at least $50 \%$ in any score (RSI, LCQ, and RFS) over baseline, as described in previous studies [15]. Patients were stratified into positive and negative response groups. Continuous variables were compared between groups with the nonparametric Mann-Whitney $U$ test because of the small sample size and abnormal distribution of some of the variables. Pearson chi-square test was used to analyze dichotomous variables. A $p$ value of less than 0.05 was considered statistically significant. Data were generated and analyzed with SPSS Version 15.0 .

\section{Results}

Forty-one patients with chronic cough completed the study. Our cohort included 25 males (61\%) and 16 females (39\%), aged 24 to 79 years (mean $55.9 \pm 15.19$ years). Among patients with chronic cough, hoarse voice was reported in $24 \%$, throat discomfort in $12.2 \%$, heartburn sensation in $63 \%$, globus sensation in $29 \%$, and depression in $7 \%$.

Following PPI treatment, the primary end point of reduction of the RSIor LCQ and/or of the RFS by more than $50 \%$ at 4 months from baseline was attained in 16 patients (39\%). The demographic and clinical characteristics of the two groups are presented in Table 1. No significant differences between groups were found for any of the variables analyzed, except for level of education which was higher in the patients with a positive response $(p=0.035)$. 
Table 1

Demographics and clinical characteristics of 41 patients with chronic cough according to response to PPI treatment

\begin{tabular}{|c|c|c|c|}
\hline Characteristics & Nonresponders $(\mathrm{N}=25)$ & $\begin{array}{l}\text { Responders } \\
(N=16)\end{array}$ & $p$ value \\
\hline Age (years), mean $\pm S D$ & $56.4 \pm 14.2$ & $54.1 \pm 17.6$ & 0.44 \\
\hline Female gender & $8(32 \%)$ & $8(50 \%)$ & 0.45 \\
\hline \multicolumn{4}{|l|}{ Place of birth } \\
\hline Israel & $16(64 \%)$ & $9(56 \%)$ & 0.81 \\
\hline East Europe & $4(16 \%)$ & $3(18.7 \%)$ & 0.84 \\
\hline West Europe & $1(4 \%)$ & $1(6.2 \%)$ & 0.76 \\
\hline North Africa & $1(4 \%)$ & $1(6.2 \%)$ & 0.76 \\
\hline North America & $3(12 \%)$ & $2(12.5 \%)$ & 0.97 \\
\hline Body mass index mean \pm SD & $27.1 \pm 5.9$ & $26.6 \pm 4.1$ & 0.53 \\
\hline \multicolumn{4}{|l|}{ Education } \\
\hline Elementary & $5(20 \%)$ & $0(0 \%)$ & 0.047 \\
\hline High school & $15(60 \%)$ & $7(43 \%)$ & 0.58 \\
\hline University & $5(20 \%)$ & $9(57 \%)$ & 0.035 \\
\hline Life with a partner & 19 & 11 & 0.24 \\
\hline No. of children & $2.43 \pm 1.24$ & $2.07 \pm 1.33$ & 0.63 \\
\hline Daily alcohol use & $1(4 \%)$ & $3(18.75 \%)$ & 0.21 \\
\hline GERD & $15(60 \%)$ & $11(68.75 \%)$ & 0.79 \\
\hline Hoarseness & $5(20 \%)$ & $5(31.25 \%)$ & 0.53 \\
\hline Throat discomfort & $3(12 \%)$ & $2(12.5 \%)$ & 0.96 \\
\hline Globus & $7(28 \%)$ & $5(31.25 \%)$ & 0.87 \\
\hline Depression & $2(8 \%)$ & $1(6.25 \%)$ & 0.84 \\
\hline Symptom duration (months) & $16.7 \pm 7.8$ & $15.3 \pm 6.2$ & 0.76 \\
\hline \multicolumn{4}{|c|}{ Data are shown as $n(\%)$ unless otherwise indicated. } \\
\hline PPI - proton pump inhibitor; G & D - gastroesophagea & $x$ disease & \\
\hline
\end{tabular}


Laryngeal findings at baseline of both groups are presented in Table 2. Scores on the self-reported instruments are shown in Tables 3 and 4. Compared with nonresponders, PPI responders (patients who achieved the primary end point) had a significantly higher rate of baseline erythema or hyperemia of the arytenoids or the postcricoid area $(p=0.026)$. At the end of the treatment period, only the responders showed a significant resolution in erythema in the posterior cricoid wall and arytenoid complex $(p=$ 0.037).

Table 2

Baseline laryngeal findings of 41 patients with chronic cough according to response to PPI treatment

\begin{tabular}{|llll|}
\hline Laryngoscope examination & Nonresponders $(\mathbf{N}=\mathbf{2 5})$ & Responders $(\mathbf{N}=\mathbf{1 6})$ & $\boldsymbol{p}$ value \\
\hline Subglottic edema & 0.3 & 0.1 & 0.09 \\
\hline Ventricular edema & 0.08 & 0.1 & 0.061 \\
\hline Erythema/hyperemia & 2.2 & 3.3 & 0.026 \\
\hline Vocal fold edema & 1.4 & 1.4 & 0.6 \\
\hline Diffuse laryngeal edema & 2 & 2.4 & 0.18 \\
\hline Posterior commissure hypertrophy & 2.2 & 2.3 & 0.23 \\
\hline Granuloma/granulation tissue & 0.08 & 0.1 & 0.061 \\
\hline Thick endolaryngeal mucus & 0.6 & 0.8 & 0.27 \\
\hline Total RFS, mean \pm SD & $9.04 \pm 3.9$ & $10.8 \pm 3.2$ & 0.16 \\
\hline *ltems were scored on a scale of 0 to 5. A higher score indicates a worse laryngeal condition. \\
\hline PPI - proton pump inhibitor; RFS - Reflux Findings Score & & \\
\hline
\end{tabular}


Table 3

Mean scores on the Leicester Cough Questionnaire of 41 patients with chronic cough according to response to PPI treatment

\begin{tabular}{|c|c|c|c|}
\hline Items & $\begin{array}{l}\text { Nonresponders } \\
(\mathrm{N}=25)\end{array}$ & $\begin{array}{l}\text { Responders } \\
(\mathrm{N}=16)\end{array}$ & $\underset{\text { value }}{p}$ \\
\hline $\begin{array}{l}\text { Have you had chest or stomach pain because of the } \\
\text { cough? }\end{array}$ & 4.6 & 4.7 & 0.51 \\
\hline $\begin{array}{l}\text { Have you been bothered by sputum (phlegm) } \\
\text { production? }\end{array}$ & 3.5 & 2.3 & 0.053 \\
\hline Have you been tired because of the cough? & 4.0 & 4.4 & 0.34 \\
\hline Have you felt in control of your cough? & 4.0 & 4.5 & 0.26 \\
\hline Have you felt embarrassed by coughing? & 6.5 & 4.1 & 0.67 \\
\hline Has the cough made you feel anxious? & 3.7 & 3.5 & 0.78 \\
\hline Has the cough interfered with your job/daily life? & 4.1 & 4.3 & 0.17 \\
\hline Has the cough interfered with your enjoyment of life? & 3.3 & 3.4 & 0.49 \\
\hline Has exposure to paint or fumes make you cough? & 4.2 & 4.3 & 0.61 \\
\hline Has the cough disturbed your sleep? & 3.6 & 3.5 & 0.82 \\
\hline How many times a day have you had coughing bouts? & 2.6 & 2.9 & 0.50 \\
\hline Has the cough made you feel frustrated? & 3.2 & 3.1 & 0.84 \\
\hline Has the cough made you feel fed up? & 3.5 & 3.4 & 0.91 \\
\hline $\begin{array}{l}\text { Have you suffered from a hoarse voice because of the } \\
\text { cough? }\end{array}$ & 4.4 & 2.09 & $\begin{array}{l}<.01 \\
0.01\end{array}$ \\
\hline Have you had a lot of energy? & 4.1 & 4.3 & 0.21 \\
\hline $\begin{array}{l}\text { Have you worried that the cough may indicate a serious } \\
\text { illness? }\end{array}$ & 4.2 & 3.8 & 0.83 \\
\hline $\begin{array}{l}\text { Have you been concerned that people think something is } \\
\text { wrong with you? }\end{array}$ & 4.5 & 4.2 & 0.67 \\
\hline Has the cough interrupted your conversations? & 5.0 & 4.9 & 0.70 \\
\hline $\begin{array}{l}\text { Have you felt that the cough is annoying your } \\
\text { partner/family? }\end{array}$ & 3.1 & 3.3 & 0.18 \\
\hline Total score & 71.5 & 73.8 & 0.54 \\
\hline \multicolumn{4}{|c|}{ Items were scored on a scale of 1 to 7 . Responses refer to the previous 2 weeks. } \\
\hline $\mathrm{PPI}=$ proton pump inhibitors & & & \\
\hline
\end{tabular}


Table 4

Mean scores on the Reflux Symptoms Index (severity and frequency) of 41 patients with chronic cough according to response to PPI treatment

\begin{tabular}{|c|c|c|c|c|c|c|}
\hline & Severity & & & Frequency & & \\
\hline Items & $\begin{array}{l}\text { Non } \\
\text { Responders } \\
(\mathrm{N}=25)\end{array}$ & $\begin{array}{l}\text { Responders } \\
(\mathrm{N}=16)\end{array}$ & $\begin{array}{l}\mathrm{p} \\
\text { value }\end{array}$ & $\begin{array}{l}\text { Non } \\
\text { Responders } \\
(\mathrm{N}=25)\end{array}$ & $\begin{array}{l}\text { Responders } \\
(\mathrm{N}=16)\end{array}$ & $\begin{array}{l}\mathrm{p} \\
\text { value }\end{array}$ \\
\hline $\begin{array}{l}\text { Hoarseness or a } \\
\text { problem with voice }\end{array}$ & 1.2 & 1.5 & 0.47 & 0.9 & 1.96 & 0.017 \\
\hline Clearing the throat & 2 & 2.2 & 0.64 & 2.3 & 2 & 0.62 \\
\hline $\begin{array}{l}\text { Excess throat } \\
\text { mucous or } \\
\text { postnasal drip }\end{array}$ & 1.78 & 1.64 & 0.83 & 1.62 & 1.09 & 0.14 \\
\hline $\begin{array}{l}\text { Difficulty } \\
\text { swallowing food, } \\
\text { liquids or pills }\end{array}$ & 0.93 & 0.27 & $\begin{array}{l}<.01 \\
0.01\end{array}$ & 1.74 & 0.55 & $\begin{array}{l}< \\
0.01\end{array}$ \\
\hline $\begin{array}{l}\text { Coughing after } \\
\text { food or after lying } \\
\text { down }\end{array}$ & 1.78 & 1.82 & 0.79 & 1.92 & 1.94 & 0.91 \\
\hline $\begin{array}{l}\text { Breathing } \\
\text { difficulties or } \\
\text { choking episodes }\end{array}$ & 0.96 & 1.09 & 0.61 & 1.92 & 2.3 & 0.54 \\
\hline $\begin{array}{l}\text { Troublesome or } \\
\text { annoying cough }\end{array}$ & 2.15 & 2.45 & 0.36 & 3.18 & 2.8 & 0.30 \\
\hline $\begin{array}{l}\text { Sensations of } \\
\text { something sticking } \\
\text { in the throat }\end{array}$ & 1.78 & 1.36 & 0.42 & 1.85 & 1.0 & 0.07 \\
\hline $\begin{array}{l}\text { Heartburn, chest } \\
\text { pain, indigestion, } \\
\text { or stomach acid } \\
\text { coming up }\end{array}$ & 1.74 & 2.09 & 0.25 & 2.22 & 1.45 & 0.12 \\
\hline Total severity & 14.07 & 13.36 & 0.53 & 18.78 & 14.55 & 0.26 \\
\hline
\end{tabular}

Analysis of the LCQ and RSI results revealed that at baseline, responders were more likely to suffer from hoarseness $(p<0.02)$. Responders had a decreased frequency and severity of difficulty in swallowing food, liquids and pills compared to nonresponders $(p<0.01)$. 
According to both the RSI and LCQ, in the group of responders, symptomatic response rate at 4 months was higher than that at 2 months (Figs. 1 and 2). Conversely, among nonresponders, lack of response at 2 months remained unchanged at 4 months.

\section{Discussion}

In the present study we have identified several factors that may be associated with response to high dose PPI, including erythema or hyperemia of the arytenoids or the postcricoid area, hoarseness, lack of dysphagia, and higher level of education. We also found that the overall response rate to esomeprazole was quite low (39\%). Similar results were presented in a retrospective study by Waxman et al. that assessed symptoms and laryngopharyngeal $\mathrm{pH}$ in patients with chronic cough who were treated with PPI [16]. These investigators also found that most patients (67.4\%) achieved symptom resolution, however $60.5 \%$ did not achieve $\mathrm{pH}$ normalization [16]. Another retrospective study, using the same PPI dosage as used in the aforementioned study, found that up to $66 \%$ of patients with chronic cough may respond to PPI [17]. Differences in response rate to PPI, as shown in these studies, may be related to the chosen criteria for the definition of response, and to the selection of symptoms. We believe that the lower response rate to PPI's in our study, may be due to the presence of alternative cough etiologies including pulmonary disease, nasopharyngeal disorders or nonacid reflux [18], despite the fact that otolaryngeal and pulmonary pathologies had ostensibly been excluded prior to inclusion [5].

We identified several positive predictors of response to PPI therapy. Patients with a good response showed higher educational attainment. This could be attributed to better compliance with therapy, thus leading to a better response rate. Additional positive predictors of response to PPI's were laryngeal findings including erythema of the arytenoids and postcricoid area. In the group of responders, laryngeal findings were the only findings that improved on PPI therapy. This may suggest that in patients with cough, erythema of the arytenoids and postcricoid area, the main underlying mechanism may be an acidic refluxate. Using a multichannel intraluminal impedance/pH monitoring, de Bortoli et al. confirmed the presence of gastroesophageal reflux in a proportion of patients with laryngeal findings [19].

We found that PPI responders complained more frequently of hoarseness and voice problems. In other prospective studies, it was found that more patients with chronic cough and the combination of throat clearing, hoarseness and voice problems, responded well to PPI [20,21]. This may be related to acidic refluxate that provokes laryngeal inflammation.

Ultimately, we found that responders reported a higher rate of symptomatic improvement at the end of the study ( 4 months) compared to the end of the 2 nd month. These results were reported by other studies that showed an increase in the response rate when PPI therapy was extended from 2 months to 4 months $[22,23]$. This time-dependent therapeutic gain was not observed in the nonresponders, suggesting that there is no basis to continue PPI therapy if there is a lack of response at 2 months.

The strengths of our study included the prospective design, the rigorous patient selection, and the use of simple and clear outcome measures.

Page $12 / 18$ 
Limitations of this study were the small sample size, the lack of a control group, and the lack of an assessment of acidic or nonacidic esophageal exposure at baseline and at the end of the 2nd and 4th months. Without an objective GERD evaluation (esophageal acid exposure study) it is impossible to determine whether or not the response to therapy was due to the reduction of esophageal acid exposure. In this study, GERD diagnosis was based on the use of questionnaires that are not sensitive and specific enough for the diagnosis of GERD. As an observational study, comparisons can only be performed in an indirect manner. Thus, there is a possibility that the association we found, may be the result of an effect of other variables that differ between exposed and non-exposed subjects, and that may also have an association with the study outcome. This study assessed a simple question in a practical and realistic clinical setting where invasive tests to evaluate GERD in chronic cough are not readily available.

Finally, we used laryngeal signs to demonstrate or to rule out response to treatment. However, the sensitivity of these signs are not perfect as some of these signs can be encountered in asymptomatic subjects.

\section{Conclusion}

In this prospective, open-label study, the response rate of chronic cough to 4 months of double dose PPI therapy was suboptimal. However, it is possible that a subset of patients who may respond to PPI therapy could potentially be identified with esophageal impedance/pH testing.

If impedance/pH recording is unavailable, we found that the presence of hoarseness, hyperemia of the arytenoids and postcricoid area, and lack of dysphagia, to be positive predictive factors for PPI response.

Moreover, we found that patients who responded to therapy in the first 2 months, benefited from continuing treatment for an additional 2 months. Therefore, our advice is to assess patients after the first 2 months therapy, and based on their response, a decision should be made whether to continue treatment.

\section{Abbreviations}

\section{GERD}

Gastroesophageal reflux disease

PPI

Proton pump inhibitors

PND

Postnasal drip

RSI

Reflux symptoms index

LCQ

Leicester cough questionnaire 
RFS

Reflux findings score

\section{Declarations}

Ethics approval and consent to participate: All study procedures were performed in accordance with the principles of the Declaration of Helsinki, Good Clinical Practice and was approved by the Human Subjects Protection Program of the Rabin Medical Center, Israel (trial 0125-13). All patients provided written informed consent before enrollment into the study. All eligible patients who gave informed consent underwent an upper endoscopy (at baseline only) if they had not done so in the past year.

Consent for publication: Not applicable

Availability of data and materials: Applicable upon request of dataset that would be necessary to interpret, replicate and build upon the findings reported in the article for all participants. Files of data and materials are available upon reasonable request to Dr. Uri Alkan.

Competing interests: The authors declare that they have no competing interests.

Funding: Not applicable

\section{Author's Contributions}

R.D., Y.V., J.S., and U,A.: Conception and design.

D.B., Y.N., R.G-B and A.B.: Acquisition of data

R.D., A.R., and U.A.: Drafting manuscript

Y.N. R.G-B and A.B.: Analysis and interpretation of data:

R.D., D.B., A.R., and U.A.: Final approval of the manuscript.

All authors read and approved the manuscript

Acknowledgements: Not applicable

\section{References}

1. Chang AB, Lasserson TJ, Kiljander TO, Connor FL, Gaffney JT, Garske LA. Systematic review and meta-analysis of randomised controlled trials of gastro-esophageal reflux interventions for chronic cough associated with gastro- esophageal reflux. BMJ. 2006;332:11.

2. French CL, Irwin RS, Curley FJ, Krikorian CJ. Impact of chronic cough on quality of life. Arch Intern Med. 1998;158:1657-61. 
3. Isolauri J, Laippala P. Prevalence of symptoms suggestive of gastro-oesophageal reflux disease in an adult population. Ann Med. 1995;27:67-70.

4. Xiao-rong Xu, Zhao-shen Li, Duo-wu Zou, Guo-ming Xu, Ping Ye, Zhen-xing Sun, et al. Role of duodenogastroesophageal reflux in the pathogenesis of esophageal mucosal injury and gastroesophageal reflux symptoms. Can J Gastroenterol. 2006;20:91-4.

5. Vakil N, van Zanten SV, Kahrilas P, Dent J, Jones R. Global Consensus Group. The Montreal definition and classification of gastroesophageal reflux disease: a global evidence-based consensus. Am J Gastroenterol. 2006;101:1900-20; quiz 1943.

6. Ing AJ, Ngu MC, Breslin AB. Pathogenesis of chronic persistent cough associated with gastroesophageal reflux. Am J Respir Crit Care Med. 1994;149:160-7.

7. .Javorkova N, Varechova S, Pecova R, Tatar M, Balaz D, Demeter M, et al. Acidification of the oesophagus acutely increases the cough sensitivity in patients with gastrooesophageal reflux and chronic cough. Neurogastroenterol Motil 2008;20:119-124.

8. Smith JA, Decalmer S, Kelsall A, McGuiness K, Jones H, Galloway S, et al. Acoustic cough-reflux associations in chronic cough: potential triggers and mechanisms. Gastroenterology 2010;139:75462.

9. Laukka MA, Cameron AJ, Schei AJ. Gastroesophageal reflux and chronic cough: which comes first? J Clin Gastroenterol. 1994;19:199-204.

10. DeVault KR, Castell DO. Updated guidelines for the diagnosis and treatment of gastroesophageal reflux disease. The Practice Parameters Committee of the American College of Gastroenterology. Am J Gastroenterol. 1999;94:1434-42.

11. Wei C. A meta-analysis for the role of proton pump inhibitor therapy in patients with laryngopharyngeal reflux. Eur Arch Otorhinolaryngol. 2016;273:3795-801.

12. Belafsky PC, Postma GN, Koufman JA. Validity and reliability of the reflux symptom index (RSI). J Voice. 2002;16:274-7.

13. Birring SS, Prudon B, Carr AJ, Singh SJ, Morgan MD, Pavord ID. Development of a symptom specific health status measure for patients with chronic cough: Leicester Cough Questionnaire (LCQ). Thorax. 2003;58:339-43.

14. Belafsky PC, Postma GN, Koufman JA. The validity and reliability of the reflux finding score (RFS) Laryngoscope. 2001;111:1313-7.

15. Cheong JH, Kim GH, Lee BE, Choi MK, Moon JY, Ryu DY, et al. Endoscopic grading of gastroesophageal flap valve helps predict proton pump inhibitor response in patients with gastroesophageal reflux disease. Scand J Gastroenterol 2011;46:789-96.

16. Waxman J, Yalamanchali S, Valle ES, Pott T, Friedman M. Effects of proton pump inhibitor therapy for laryngopharyngeal reflux on posttreatment symptoms and hypopharyngeal $\mathrm{pH}$. Otolaryngol Head Neck Surg. 2014;150:1010-7. 
17. Amin MR, Postima GN, Johnson P, Digges N, Koufman JA. Proton pump inhibitor resistance in the treatment of laryngopharyngeal reflux. Otolaryngol Head Neck Surg. 2001;125:374-8.

18. Guo H, Ma H, Wang J. Proton pump inhibitor therapy for the treatment of laryngopharyngeal reflux: a meta-analysis of randomized controlled trials. J Clin Gastroenterol. 2016;50:295-300.

19. de Bortoli N, Nacci A, Savarino E, Martinucci I, Bellini M, Fatgtori B, et al.How many cases of laryngopharyngeal reflux suspected by laryngoscopy are gastroesophageal reflux disease-related? World J Gastroenterol 2012;18:4363-70.

20. Noordzij JP, Khidr A, Evans BA, Desper E, Mittal RK, Reibel JF, et al. Evaluation of omeprazole in the treatment of reflux laryngitis: a prospective, placebo-controlled, randomized, double-blind study. Laryngoscope 2001;111:2147-51.

21. Noordzij JP, Khidr A, Desper E, Meek RB, Reibel JF, Levine PA. Correlation of pH probe-measured laryngopharyngeal reflux with symptoms and signs of reflux laryngitis. Laryngoscope. 2002;112:2192-5.

22. Williams RB, Szczesniak MM, Maclean JC, Brake HM, Cole IE, Cook IJ. Predictors of outcome in an open label, therapeutic trial of high-dose omeprazole in laryngitis. Am J Gastroenterol.2004;99:77785.

23. Park W, Hicks DM, Khandwala F, Richter JE, Abelson TI, Milstein C, et al. Laryngopharyngeal reflux: prospective cohort study evaluating optimal dose of proton-pump inhibitor therapy and pretherapy predictors of response. Laryngoscope 2005;115:1230-8.

\section{Figures}


Figure 1

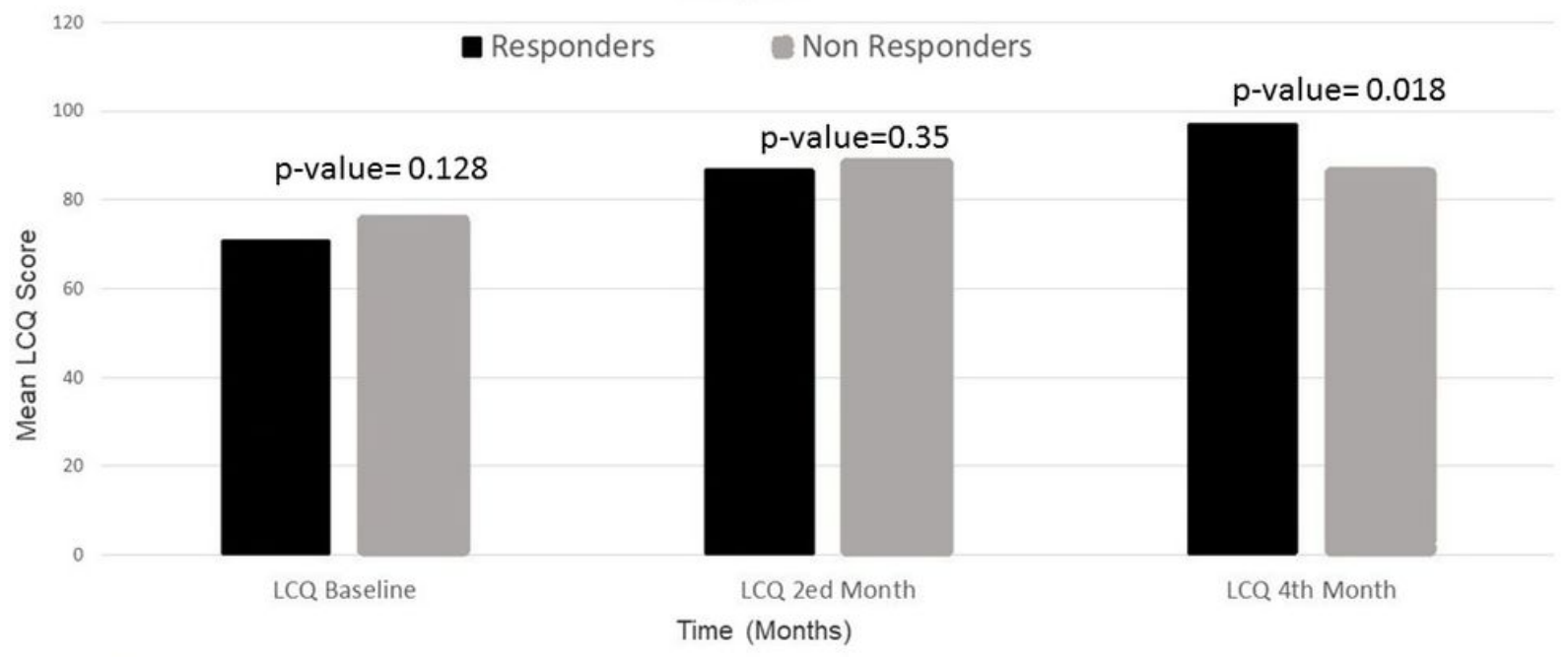

\section{Figure 1}

Mean scores on the Leicester Cough Questionnaire (LCQ) in responders and nonresponders at baseline and after 2 and 4 months of proton pump inhibitor (PPI) treatment. A lower score indicates that patients have more severe symptoms. 
Figure 2

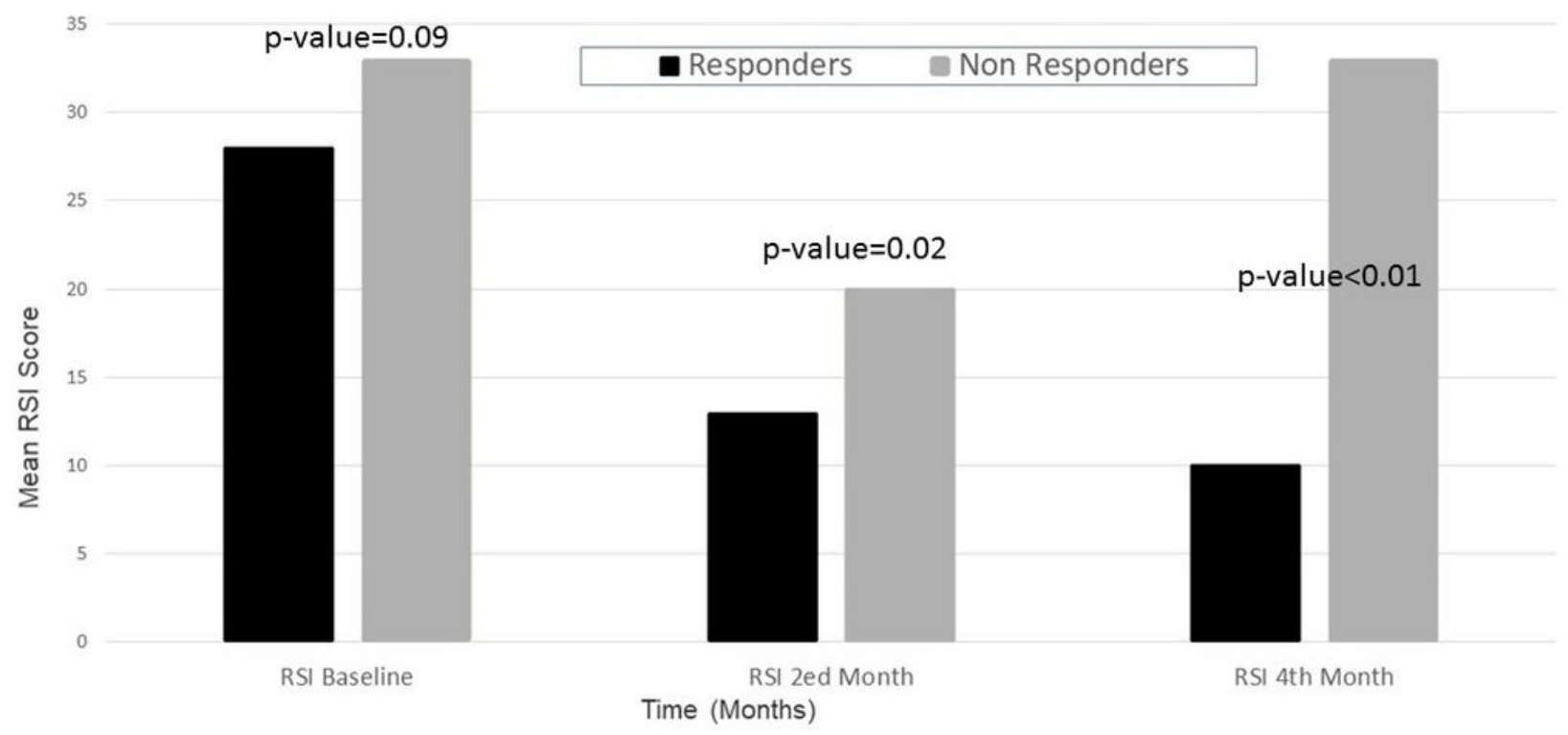

Figure 2

Mean scores on the Reflux Symptoms Index (RSI) in responders and nonresponders at baseline and after 2 and 4 months of proton pump inhibitor (PPI) treatment. 